\title{
Morusin suppresses breast cancer cell growth in vitro and in vivo through C/EBP $\beta$ and PPARY mediated lipoapoptosis
}

\author{
Haiyan Li ${ }^{\dagger}$, Qiaoping Wang ${ }^{\dagger}$, Lihua Dong, Chuanlan Liu, Zhen Sun, Ling Gao and Xiujie Wang*
}

\begin{abstract}
Background: Breast cancer is the most fatal malignant cancer among women, the conventional therapeutic modalities of it are limited. Morusin possesses cytotoxicity against some cancer cells in vitro. The purpose of this study is to test the growth inhibition effect of morusin on human breast cancer growth in vitro and in vivo and to explore the potential mechanism of its action.

Methods: The growth inhibition effect of morusin on human breast cancer cells in vitro and in vivo were tested by cell cytotoxicity, colony formation inhibition, adipogenic differentiation, apoptosis induction, and tumor growth inhibition in vivo assays. The potential molecular mechanisms underlying the growth inhibition effect of morusin on human breast cancer cells in vitro and in vivo were investigated with Western blotting evaluation of expression levels of transcription factors, C/EBP $\beta$ and PPARY, adipogenic and apoptotic proteins in morusin treated breast cancer cells and tumor tissues.
\end{abstract}

Results: Morusin inhibited breast cancer cells growth in vitro and in vivo; it induced adipogenic differentiation, apoptosis and lipoapoptosis of cancer cells.

Conclusions: Morusin has the potential to inhibit human breast cancer cell growth in vitro and in vivo through C/EBP $\beta$ and PPARY mediated lipoapoptosis.

Keywords: Morusin, Breast cancer, Growth inhibition, Adipogenic differentiation, Apoptosis, Lipoapoptosis

\section{Background}

Breast cancer is one of the most prevalent cancers and the leading cause of cancer death among women worldwide [1]. Despite the significant advances in breast cancer treatment modalities and improvement of patients' survival and quality of life in recent decades, its incidence and mortality are increasing steadily, especially in developing countries [1-3]. Currently, the conventional therapeutic strategies such as surgery, radiotherapy, and chemotherapy are limited treatment options for breast cancer. Although breast cancer patients with estrogen receptor positive $(E R+)$ have a better outcome after endocrine therapy, one-third of them are not sensitive to Tamoxifen, and the rest of them have a risk of relapse

\footnotetext{
* Correspondence: xiujiewang@scu.edu.cn

${ }^{\dagger}$ Equal contributors

Laboratory of Experimental Oncology,State Key Laboratory of Biotherapy/ Collaborative Innovation Center for Biotherapy, West China Hospital, West China Clinical Medical School, Sichuan University, Chengdu 610041, China
}

$[4,5]$; The subtype, "Triple Negative Breast Cancer" (TNBC), is more aggressive and resistance to available treatments, there has no available therapeutics for it $[6,7]$. Therefore, the identification of effective chemopreventive agents and development of neoadjuvant chemotherapies with alternative strategic options are crucial for ER+ breast cancer and TNBC [8-11].

Previous investigations revealed natural products process anticancer activity and selectivity of anti-cancer agents [12, 13], flavonoids provide a diversity of anticancer compounds which can be used for breast cancer prevention and/or treatment [14].

Morusin is a prenylated flavonoid derived from the root bark of Morusaustralis (Moraceae) [15] and branch bark of Ramulus mori [16], possesses anti-oxidant and anti-inflammatory activities [17]. It exhibited cytotoxicity against some human cancer cells in vitro, including colorectal cancer [15], prostate cancer [17], breast cancer, 
cervical cancer and liver cancer cells [18, 19], prevents neuronal cells from nitrosative stress-mediated cell death [20], and inhibits the tumor growth of murine hepatocarcinoma in vivo without side effects [11]. Our previous studies showed that morusin inhibited the proliferation and migration of human cervical CSCs through reduction of NF-kBp65 activity and apoptosis induction [21], suppressed glioblastoma stem cell growth in vitro and in vivo through stemness attenuation, adipocyte transdifferentiation and apoptosis induction [22].

In light of these findings, it could be assumed that morusin might serve as a novel therapeutic agent for cancer therapy, But its anticancer efficiency and profile needs to be confirmed further, and the mechanism of action is elusive [17-22]. Therefore, in the present study, we investigated the growth inhibition effect of morusin on human breast cancer cells in vitro and in vivo and characterized its potential mechanism of anticancer activity.

\section{Methods}

Reagents

DMEM media and fetal bovine serum (FBS) were purchased from Invitrogen (Shanghai, China). Trypsin, 3-(4, 5-dimethylthiazol-2-yl)-2, 5-diphenyltetrazolium bromide (MTT), DMSO and other chemicals and reagents were obtained from Sigma-Aldrich (Shanghai, China). Morusin was purchased from Chengdu Biopurify Phytochemicals Ltd. (Chengdu, China, purity $\geq 98 \%$ HPLC).

\section{Cell line and culture}

Human normal mammary epithelial cells, MCF-10A, murine breast cancer cells (4 T1 and EMT6) and human breast cancer cells (MCF-7 and MDA-MB-231) were obtained from Shanghai Cell Biology Institute of Chinese Academy of Sciences (Shanghai, China), and were maintained in DMEM medium with $10 \%$ fetal bovine serum, penicillin $(100 \mathrm{U} / \mathrm{ml})$ and streptomycin $(100 \mu \mathrm{g} / \mathrm{ml})$ at $37{ }^{\circ} \mathrm{C}$ in the presence of $5 \% \mathrm{CO}_{2}$.

\section{Cytotoxicity assay (MTT)}

The cytotoxicity of morusin against human normal mammary epithelial cells and murine breast cancer cells (4 T1 and EMT6) and human breast cancer cells (MCF-7 and MDA-MB-231) was tested by modified MTT assay [23]. Briefly, human normal mammary epithelial cells MCF-10A, and breast cancer cells, MCF-7 and MDAMB-231, $\left(1 \times 10^{3} /\right.$ well $)$ were seed in $100 \mu \mathrm{l}$ of medium/ well in 96-well plates. After overnight incubation, the cells were then treated with various concentrations of morusin $(1,2,4,6$ and $8 \mu \mathrm{g} / \mathrm{ml})$, each concentration containing 3 wells. After treatment with morusin for 1, 2, 3, 4, and 5 days, $20 \mu \mathrm{l}$ MTT (pH 4.7) was added to each well, and cultivated for another $4 \mathrm{~h}, 100 \mu \mathrm{L}$ of $10 \%$ SDS/0.01 N $\mathrm{HCl}$ was added and incubated at $37{ }^{\circ} \mathrm{C}$ overnight to dissolve the formazan. Absorbance was measured at $570 \mathrm{~nm}$, the effect of morusin on the viabilities of normal mammary epithelial cells, MCF-10A and breast cancer cells, MCF-7 and MDA-MB-231 were expressed as the \% cytoviability, using the following formula: $\%$ cytoviability = $\mathrm{A}_{570}$ of treated cells/ $\mathrm{A}_{570}$ of control cells $\times 100 \%[23,24]$, Three independent experiments were performed.

\section{Colony formation inhibition assay}

The clonogenic potential of breast cancer cells was determined by seeding 300 human breast cancer cells per well in 6-well plates, the cells were incubated for approximately $24 \mathrm{~h}$, and then treated with 1,2 , and $3 \mu \mathrm{g} / \mathrm{ml}$ of morusin, respectively. After 12 days of incubation, the cells were stained with $0.5 \%$ crystal violet in absolute ethanol and colonies with $>50$ cells were counted under dissection microscope. Three independent experiments were conducted, each in triplicate.

\section{DAPI staining apoptotic cells}

Apoptotic morphology-nuclear chromatin condensation was examined with DAPI staining. MCF-7 and MDA-MB231 cells were seeded in 6-well plates. After incubation overnight, cells were treated with different concentrations of morusin $(4,6,8 \mu \mathrm{g} / \mathrm{ml})$ for $48 \mathrm{~h}$. Subsequently, cells were harvested, fixed in $4 \%$ paraformaldehyde, treated with $0.25 \%$ Triton X-100 in TBS for $15 \mathrm{~min}$ at room temperature and stained with $50 \mu \mathrm{l}$ DAPI $(4 \mathrm{mg} / \mathrm{mL}$, Sigma, Aldrich) for $30 \mathrm{~min}$ at room temperature. After washing with PBS, samples were stored in the dark at $4{ }^{\circ} \mathrm{C}$ and examined under a fluorescence microscope [25], three independent experiments were conducted.

\section{Annexin V-FITC/PI double staining apoptotic cells}

Detection of apoptotic cells was performed using the Annexin V-FITC/PI apoptosis detection kit (Beyotime Biotech, Shanghai, China) according to manufacturer's instructions. Briefly, cancer cells treated with 4, 6, and $8 \mu \mathrm{g} / \mathrm{ml}$ of morusin, respectively, for $36 \mathrm{~h}$ were washed with PBS and stained simultaneously with FITCconjugated Annexin V and PI at room temperature for $15 \mathrm{~min}$ in the dark. The apoptotic cells were measured using a FACScalibur flow cytometer and Cell Quest Pro software (BD Biosciences, Shanghai, China). Three independent experiments were performed.

\section{Cell cycle analysis (FCM)}

Cell cycle distribution was analyzed by flow cytometry (FCM). Briefly, $1 \times 10^{6}$ cells were harvested from the control and breast cancer cells treated with $4,6,8 \mu \mathrm{g} / \mathrm{ml}$ of morusin for $36 \mathrm{~h}$, washed twice with PBS and fixed in $70 \%$ ice-cold ethanol for $1 \mathrm{~h}$. The sample was then 
concentrated by removing ethanol and treated with $1 \%$ $(\mathrm{v} / \mathrm{v})$ Triton X-100 and $0.01 \%$ RNase for $10 \mathrm{~min}$ at $37{ }^{\circ} \mathrm{C}$. Cellular DNA was stained with $0.05 \%$ propidium iodide for $20 \mathrm{~min}$ at $4{ }^{\circ} \mathrm{C}$ in darkness. Cell cycle distribution were analyzed with FCM (Cytomics ${ }^{\text {TM }}$ FC500,Beckman Coulter) and MultiCycle software package (Phoenix, USA). All data represents the results from three independent experiments.

\section{Tumor growth inhibition test in vivo}

15 six-week-old female nude mice were inoculated with $2 \times 10^{6}$ human breast cancer cells (MCF-7) subcutaneously. After 5 days of tumor cell inoculation, tumor bearing mice were randomized into three groups, each having five mice. Two treatment group mice were injected with 5 and $10 \mathrm{mg} / \mathrm{kg}$ of morusin i.p. three times weekly for 4 weeks, respectively, and the control mice were injected with DMSO. During the experiment, mice were weighted, and tumor volumes were measured weekly using calipers and their volumes were calculated using a standard formula (length $\times$ width $^{2} \times 0.5$ ) [26]. At the end of experiment, the mice were sacrificed by carbon dioxide asphyxiation; tumor masses were dissected, and weighed. The tumor inhibitory rates were calculated using the following formula: tumor inhibitory rate $(\%)=($ mean tumor weight of the control mice mean tumor weight of the treated mice) $\div$ mean tumor weight of the control mice $\times 100 \%$. The experiment was performed under standard conditions according to the guidelines of the Institutional Animal Care and Use Committee of Sichuan University.

\section{Oil Red $O$ staining}

Breast cancer cells treated with 2 , and $4 \mu \mathrm{g} / \mathrm{ml}$ of morusin for $72 \mathrm{~h}$, respectively, the cells were fixed with $100 \%$ methanol, washed in PBS; cryostat sections of the control and morusin treated tumor tissues were prepared regularly. Both the cells and cryostat sections of tumor tissues were stained with Oil Red O stain for $20 \mathrm{~min}$ at room temperature [27]. After incubation, slides were differentiated with an $85 \%$ propylene glycol solution for $1 \mathrm{~min}$, rinsed in water, and counterstained with Mayer's Hematoxylin and observed under microscope.

\section{Western blot analysis}

Both morusin treated breast cancer cells and tumor tissues were lysated with RIPA lysis buffer, centrifuged, the supernatants were collected and quantified with UV

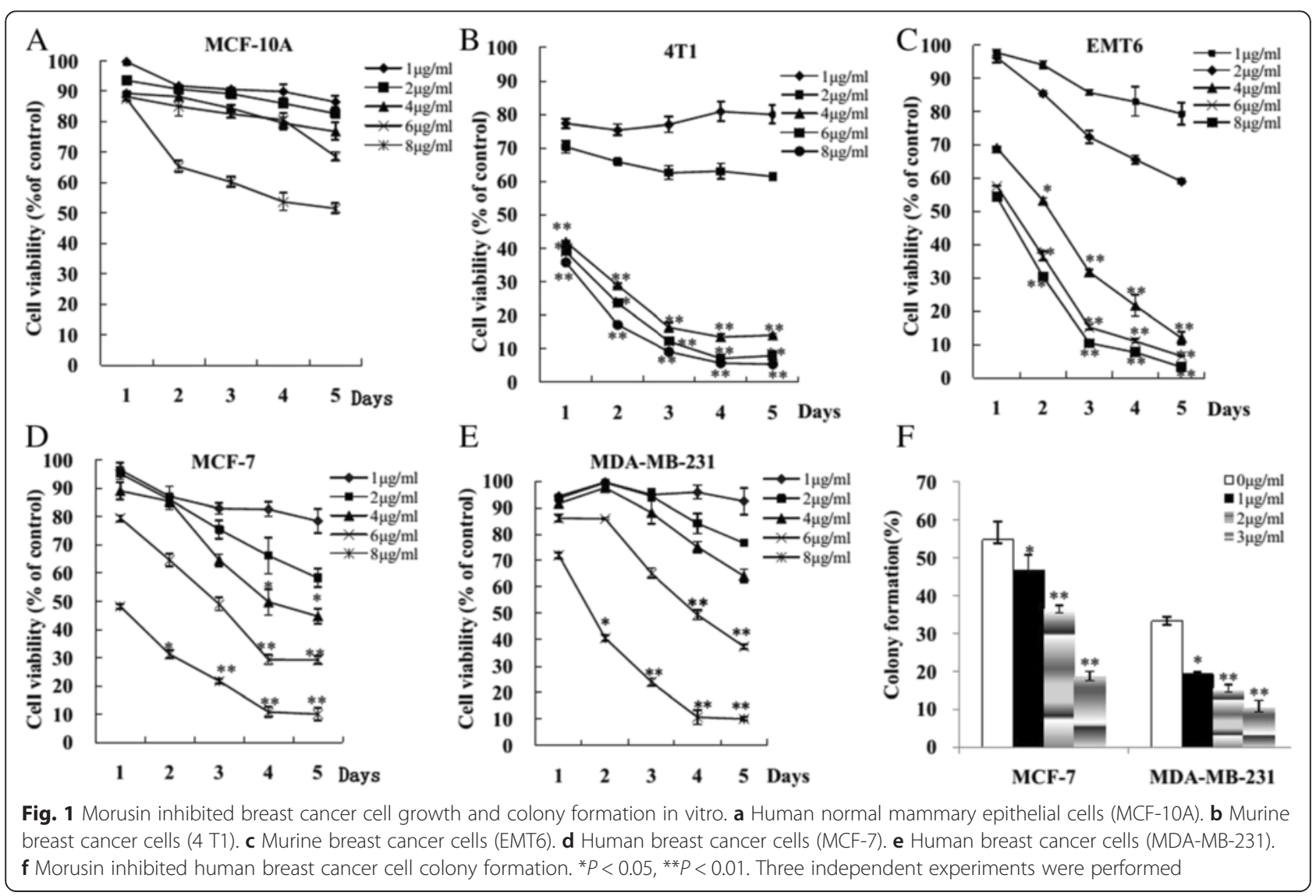


spectrophotometer. Samples containing $30 \mu \mathrm{g}$ protein were mixed with loading buffer $(5 \times)$, boiled for $5 \mathrm{~min}$, separated by $12 \%$ SDS-PAGE, transferred PVDF membranes using a semi-dry blotting apparatus (Bio-Rad, Hercules, CA, USA), and then blocked in $5 \%$ non-fat milk at RT for $1 \mathrm{~h}$. The PVDF membranes were incubated with primary antibodies of rabbit anti-C/EBP $\beta$,rabbit anti-PPAR $\gamma$, rabbit anti-adipsin $\mathrm{D}$,rabbit antiperilipin $\mathrm{A}+\mathrm{B}$, rabbit anti-Bcl-2, rabbit anti-Bax, rabbit anti-active caspase- 3 and rabbit anti- $\beta$-actin (Beijing Biosynthesis Biotechnology Co., LTD, Beijing, China) diluted 1:300. Antibody recognition was detected with peroxidase-conjugated goat anti-rabbit $\operatorname{IgG}(\mathrm{H}+\mathrm{L})$ secondary antibody (Zhongshan Goldenbridge Biotechnology Co., LTD, Beijing, China) used at 1:6000 dilutions, antibody-bound proteins were detected by Chemiluminescent HRP Substrate (Milipore Corporation, Billera, USA) and western blotting analysis system (Universal Hood II,
Bio-Rad, USA), and normalized to $\beta$-actin and semiquantified using the ChemiDocTM XRS (Bio-Rad, USA).

\section{Statistical analysis}

The data were expressed as mean \pm standard deviation (Mean $\pm \mathrm{SD}$ ). All data were analyzed using the software SPSS V 16.0. Independent sample $t$-test was used to analyze the statistical difference. Statistical significance was defined as $p<0.05$ for all tests.

\section{Results}

Morusin inhibits murine and human breast cancer cell proliferation

The proliferation inhibition effect of morusin on human normal mammary epithelial cells (MCF-10A) and breast cancer cells is shown in Fig. 1. Morusin exhibited a dose- and time-dependent inhibitory effect on murine and
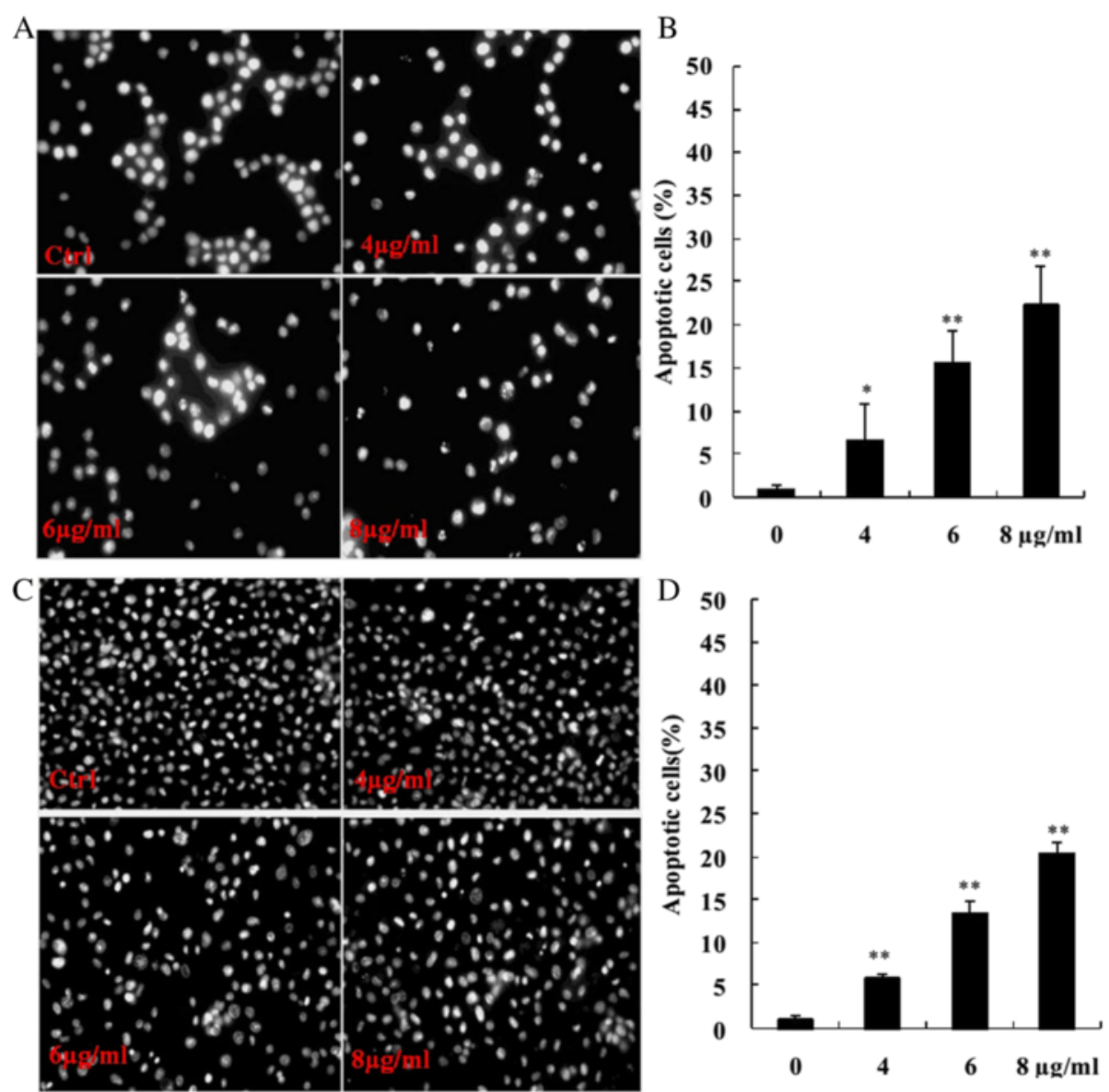

Fig. 2 DAPI stained apoptotic cells in morusin treated MCF-7 and MDA-MB-231 breast cancer cells. a DAPI stained apoptotic cells in morusin treated MCF-7 cells. b The histogram shows that there was significant increase of AO/EB stained apoptotic cells in morusin treated MCF-7 cells. c DAPI stained apoptotic cells in morusin treated MDA-MB-231 cells. $\mathbf{d}$ The histogram shows that there was significant increase of DAPI stained apoptotic cells in morusin treated MDA-MB-231 cells. ${ }^{*} P<0.05,{ }^{*} P<0.01$. Three independent experiments were performed 
human breast cancer cells $(\mathrm{p}<0.01)$. $\mathrm{IC}_{50}$ was $9.48 \mu \mathrm{g} / \mathrm{ml}$ for normal mammary epithelial cells (MCF-10A); 2.03 and $1.87 \mu \mathrm{g} / \mathrm{ml}$ for murine breast cancer cells (4 T1 and EMT6); and 2.71 and $3.86 \mu \mathrm{g} / \mathrm{ml}$ for human breast cancer cells (MCF-7 and MDA-MB-231), respectively, the maximal inhibition of cell growth $(>80 \%)$ was obtained at $8 \mu \mathrm{g} / \mathrm{ml}$ (Fig. 1b, c, d, e).

\section{Morusin inhibits breast cancer cell colony formation}

Colony formation rates of untreated MCF-7 and MDA-MB-231breast cancer cells were $54.83 \pm 4.75$ and $33.33 \pm 1.04 \%$, respectively. After treatment with 1,2 , and $3 \mu \mathrm{g} / \mathrm{ml}$ of morusin, Colony formation rates of MCF-7 cells were $46.67 \pm 4.04,36.50 \pm 3.50$ and $18.50 \pm 1.50 \%$, respectively; the rates of MDA-MB-23 cells were $19.33 \pm 0.58,15.50 \pm 0.87$ and $10.33 \pm 1.10 \%$, respectively. Dose-dependent colony-forming inhibitory effect was observed in both MCF-7 and MDA-MB-231breast cancer cells (Fig. 1f).

\section{Apoptotic cell detection by DAPI staining}

The cells with condensed chromatin and stained bright with DAPI morphologically were apoptotic cells. Apoptotic cells in the untreated human breast cancer cells MCF-7 and MDA-MB-231 were $1.11 \pm 0.37 \%$ and $1.12 \pm 0.47 \%$, respectively. After treatment with $4,6,8 \mu \mathrm{g} / \mathrm{ml}$ of morusin for $48 \mathrm{~h}$, the apoptotic cells in breast cancer cells, MCF-7 were $6.7 \pm 4.09,15.70 \pm 3.63$, and $22.50 \pm 4$. $3 \%$, respectively; and in MDA-MB-231 cells, the apoptotic cells were $5.9 \pm 0.51,13.5 \pm 1.4,20.5 \pm 1.3 \%$, respectively. The apoptotic cells in morusin treated breast cancer cells were increased significantly in a dose-dependent manner $(p<0.01$, Fig. 2).

\section{Apoptotic cell detection by FCM}

Annexin-V-FITC/PI double staining assay and FCM analyses showed that apoptotic cells in the untreated human breast cancer cells MCF-7 and MDA-MB-231 were $4.70 .11 \pm 1.41$ and $3.90 \pm 1.27 \%$, respectively, after
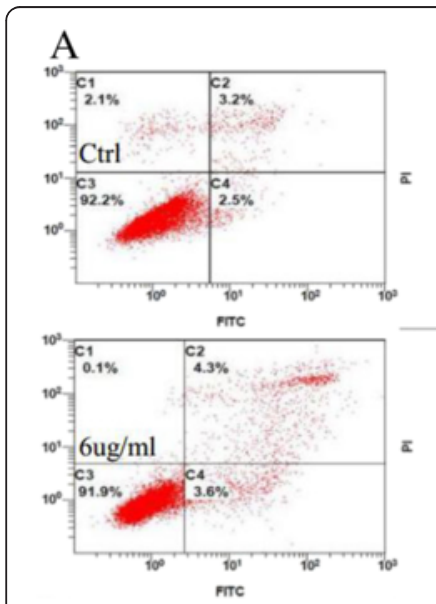

C
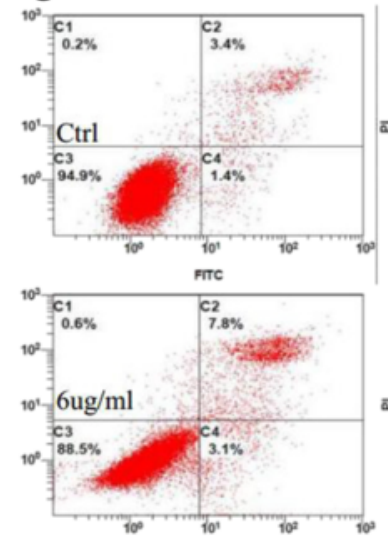
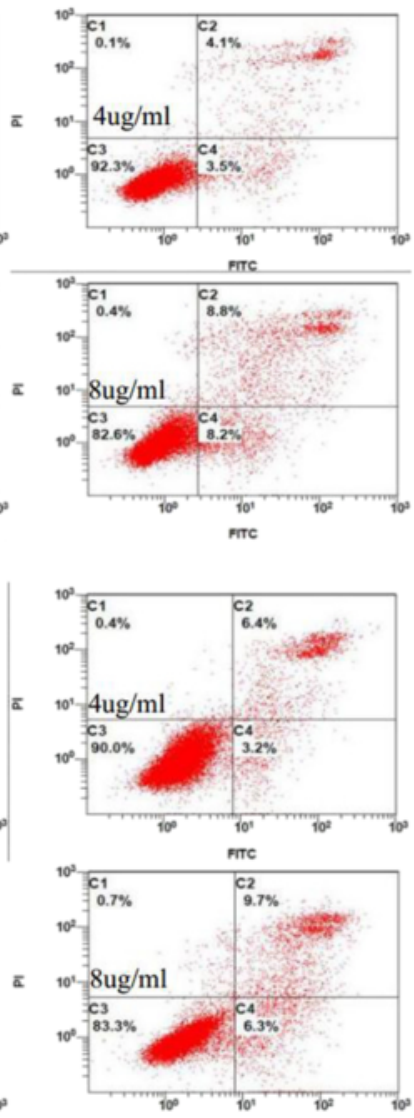

B

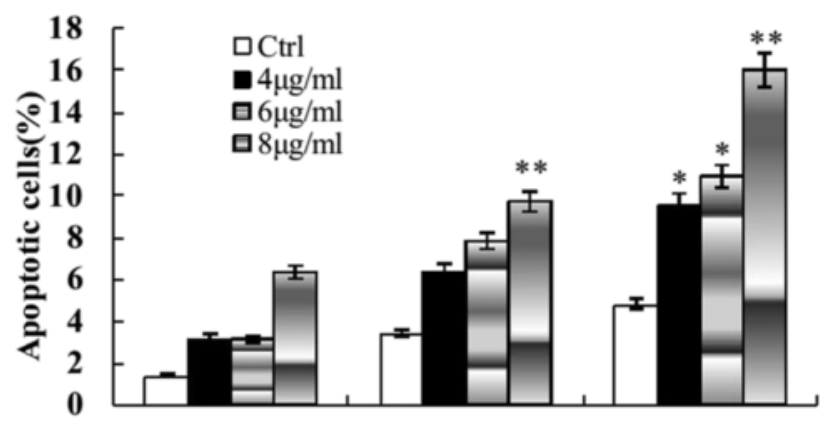

Early apoptotic Late apoptostic Total apoptotic cells cells

D

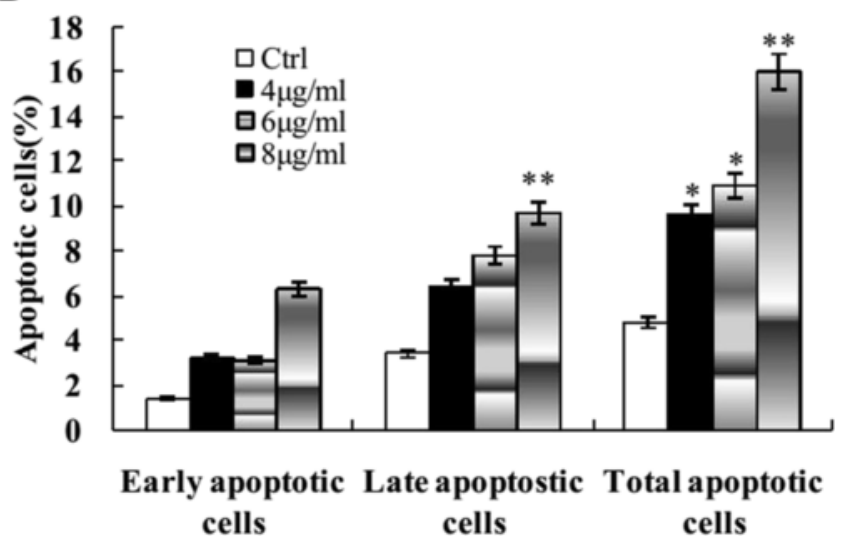

Fig. 3 Annexin V-FITC stained apoptotic cells. a Morusin induces apoptosis of MCF-7 cells. $\mathbf{b}$ The histogram shows the significant increase of apoptotic cells in MCF-7 cells after treatment with morusin in a dose dependent manner. c Morusin induces apoptosis of MDA-MB-231 cells. d The histogram shows the significant increase of apoptotic cells in MDA-MB-231cells after treatment with morusin in a dose dependent manner. ${ }^{*} P<0.05,{ }^{*} P<0.01$. Three independent experiments were performed 
treatment with $4,6,8 \mu \mathrm{g} / \mathrm{ml}$ of morusin for $48 \mathrm{~h}$, the apoptotic cells in the treated cancer cells increased significantly $(p<0.01$, Fig. 3$)$, in a dose-dependent manner.

\section{Flow cytometric analysis of cell cycle distribution}

Cell cycle analysis was performed in MCF-7 and MDAMB-231 cells after morusin treatment. Morusin treatment increased the cell population in $G_{0} / G_{1}$ phase and decreased the cell population in $S$ phase in a dose dependent manner in both MCF-7 and MDA-MB231cancer cells (Fig. 4).

\section{Morusin inhibited breast growth in vivo}

The result of tumor growth inhibition of morusin on human breast cancer generated from MCF-7 cells is shown in Fig. 5. To evaluate the growth inhibition effect of morusin on human breast in vivo, human breast cancer bearing-mice were injected with 5 and $10 \mathrm{mg} / \mathrm{kg}$ of morusin i. p., 3 times weekly for 4 weeks. Morusin retarded the growth of breast cancer significantly $(p<0.01$, (Fig. 5b). Mean tumor weight of the control mice was $1.14 \pm 0.30 \mathrm{~g}$, and those of the mice administrated with 5 and $10 \mathrm{mg} / \mathrm{kg}$ of morusin were $0.61 \pm 0.23$ and $0.41 \pm 0.10$ g, respectively (Fig. $5 \mathrm{c}$ ), tumor inhibitory

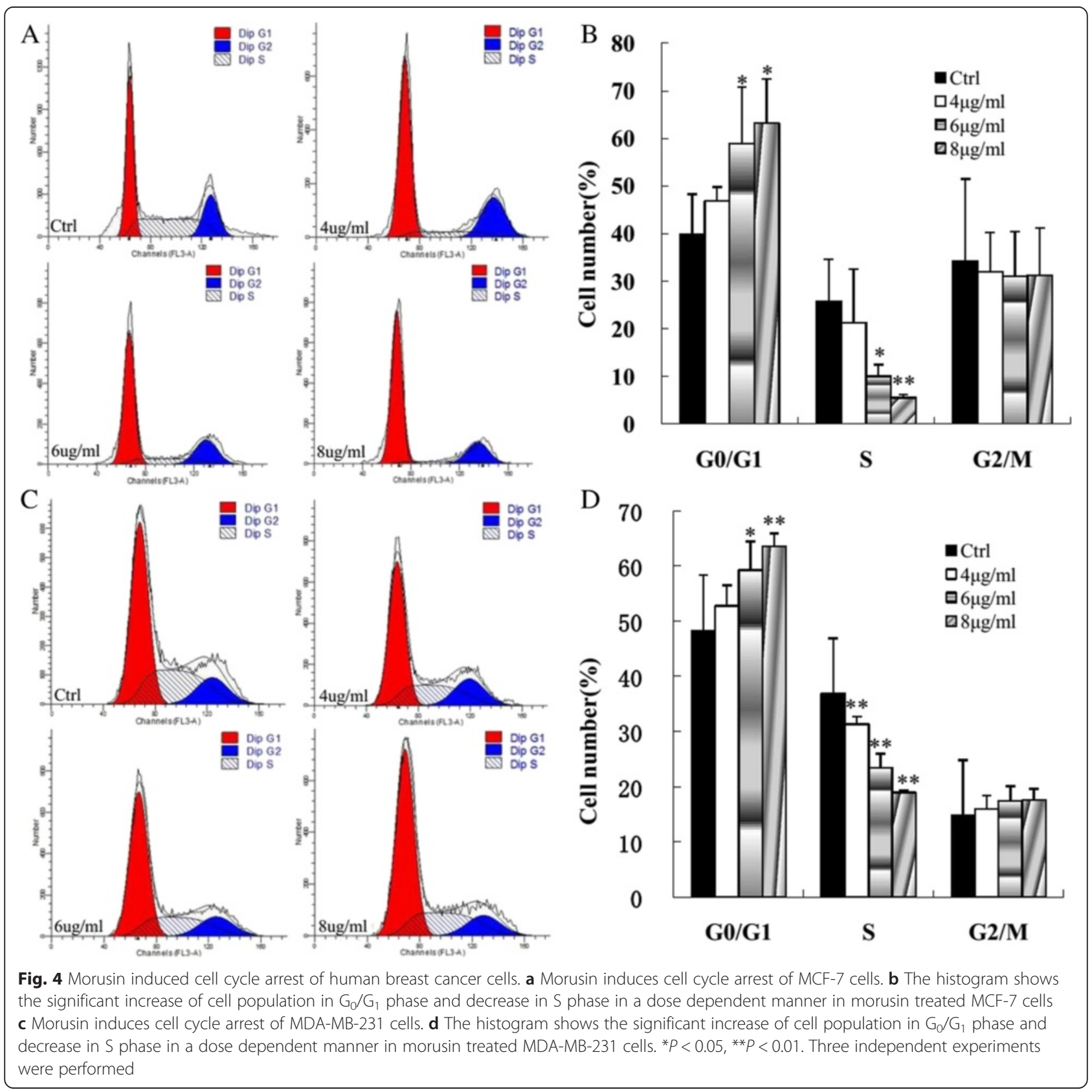



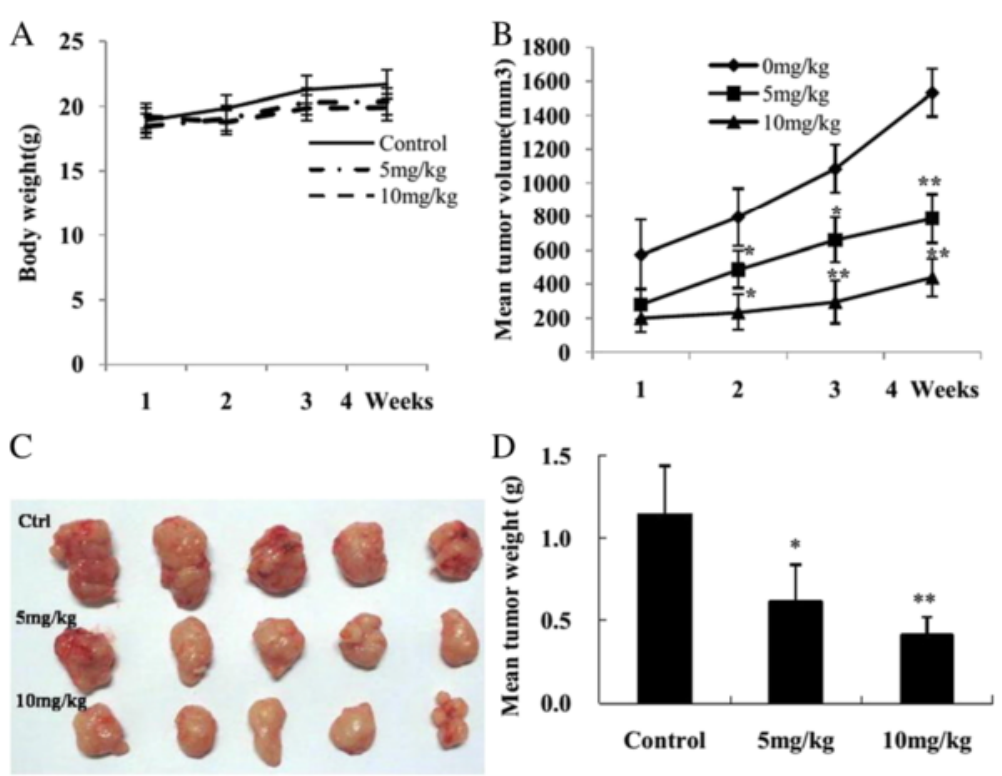

Fig. 5 Morusin inhibited human breast cancer growth initiated from MCF-7 breast cancer cells in vivo. a Body weight changes of each group after morusin treatment. $\mathbf{b}$ Tumor volume changes of each group after morusin treatment. c Tumor masses of each group. $\mathbf{d}$ The histogram shows that there was a significant difference of mean tumor weight of each morusin treated group compared with the control. ${ }^{*} P<0.05$, ** $P<0.01$

rates were $46.5 \%(p<0.05)$, and $64.1 \%(p<0.01)$, respectively (Fig. 5d). No obvious evidence of toxicity was observed in treated animals by comparing the body weight increase (Fig. 5a), histopathological changes of major organs of both the control and treated animals.

\section{Adipocyte-like differentiation effect of morusin on breast cancer cells}

Fat vacuole accumulation was observed in morusin treated breast cancer cells and tumor tissues, staining of these cells with oil red $\mathrm{O}$ showed that these vacuoles were lipid droplets and located in the cytoplasm around the nucleus, lipid droplets were increased in a dosedependent manner (Fig. 6).

\section{Morusin affected adipogenic and apoptotic protein expressions in vitro and in vivo}

To explore the potential molecular mechanisms underlying the growth inhibition effect of morusin on human breast cancer cells in vitro and in vivo, transcription factors $\mathrm{C} / \mathrm{EBP} \beta$ and PPAR $\gamma$, adipogenic and apoptotic proteins in morusin treated breast cancer cells and tumor tissues were evaluated with Western blotting. Expressions of transcription factors C/EBP $\beta$ and PPAR $\gamma$, adipogenic proteins including adipsin $\mathrm{D}$ and perilipin, were increased significantly (Fig. 7, $p<0.05$ ); In expressions of apoptotic proteins, $\mathrm{Bcl}-2$ were decreased, Bax and active caspaes-3 were increased significantly (Fig. 8, $p<0.05)$ in a dose-dependent manner in both of morusin treated breast cancer cells and tumor tissues compared with the controls.

\section{Discussion}

Breast cancer is most common malignant cancer, remains a leading cause of cancer-related death internationally. It is considered as a major public health problem around the world [1, 2, 28]. Its increasing incidence and mortality urgently needs identification and development of new and effective treatment options and chemopreventive strategies [8-11].

Flavonoids are present everywhere in nature, different flavonoids exhibited specific anticancer activities and could be purposely used both in cancer treatment as well as in chemoprevention [29], and some flavonoids are useful for prevention or treatment of breast cancer [14]. Prenylated flavonoids are a unique class of naturally occurring flavonoids that exist especially for the plant's self-defensive function, the prenylation brings prenylated flavonoids with antibacterial, anti-inflammatory, antioxidant, cytotoxicity and estrogenic activities, thus, their bioactivities and action mechanisms need to be further investigated [30].

Morusin is a prenylated flavonoid isolated from the root bark of Morusaustralis and branch bark of Ramulus mori $[15,16]$, it can also be synthesized [17]. Existed studies showed morusin processes cytotoxicity against some human cancer cells in vitro [15-21] with little side effects [16, 17]. However, its anticancer efficiency and 


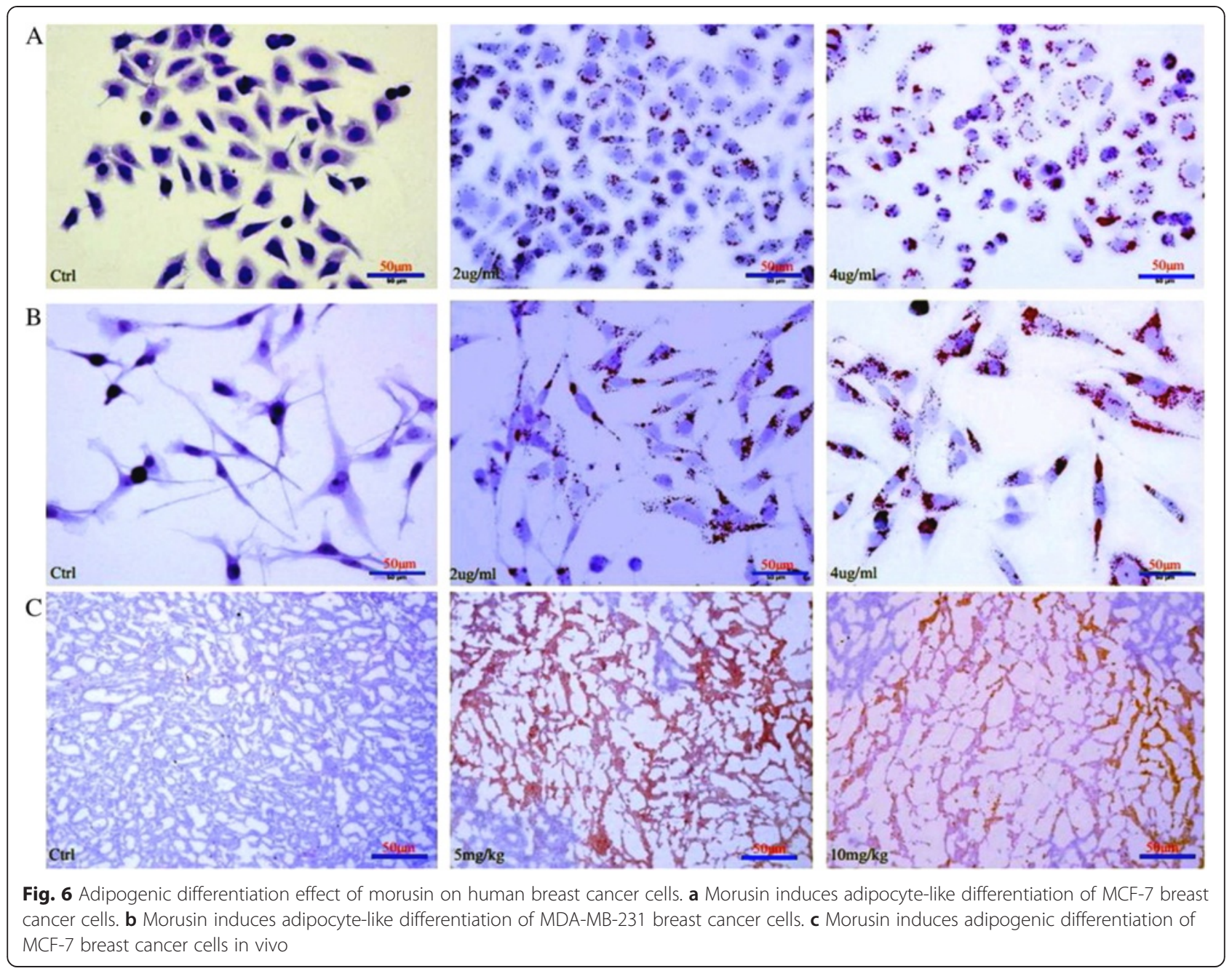

profile in vivo needs to be confirmed and its mechanism of activity remains to be elucidated [17-22].

In the present study, murine and human breast cancer cells, including ER+ breast cancer cells (MCF-7, ER $\alpha+$ ) and TNBC cells (MDA-MB-231 and 4 T1) were treated with morusin, the cell proliferation of cancer cells were suppressed in dose and time-dependent manner (Fig. 1), the colony growth potential of cancer cells was inhibited in a dose-dependent manner (Fig. $1 \mathrm{~d}, p<0.01$ ), and little cytotoxicity to normal mammary epithelial cells was noted (Fig. 1a).

Inducing apoptosis and cell cycle arrest are two main strategies for cancer treatment, many anticancer agents target rapidly cycling tumor cells, induce them cell cycle arrest and apoptotic death, and inhibit tumor growth in vivo [30-32].

After treatment with morusin, apoptotic cells were increased significantly in a dose-dependent manner $(p<0.01$, Figs. 2 and 3$)$, cell cycle arrest of morusin treated cancer cells was verified with flow cytometry analysis, the cell numbers in $G_{0} / G_{1}$ phases were increased and decreased in $S$ phase significantly $(p<0.01$, Fig. 4$)$ in morusin treated cancer cells, which are the important hallmarks of apoptosis [33-35].

In vivo experiment,morusin supressed the growth of human breast cancer in vivo, reduced the volume and weight of tumor masses significantly $(p<0.01$, Fig. 5), without evident toxicity [16, 22]. It is suggested that morusin might have potential anticancer activity on human breast cancer in vivo.

Furthermore, when breast cancer cells were exposed to low concentrations of morusin $(2-6 \mu \mathrm{g} / \mathrm{ml})$ in vitro, most cells survived and differentiated into adipocyte-like cells. In addition, focal adipogenetic differentiation was detected in morusin treated breast cancer tissues (Fig. 6).

To explore the molecular mechanisms of the growth inhibition effect of morusin on human breast cancer cells in vitro and in vivo, transcription factors $C / E B P \beta$ 


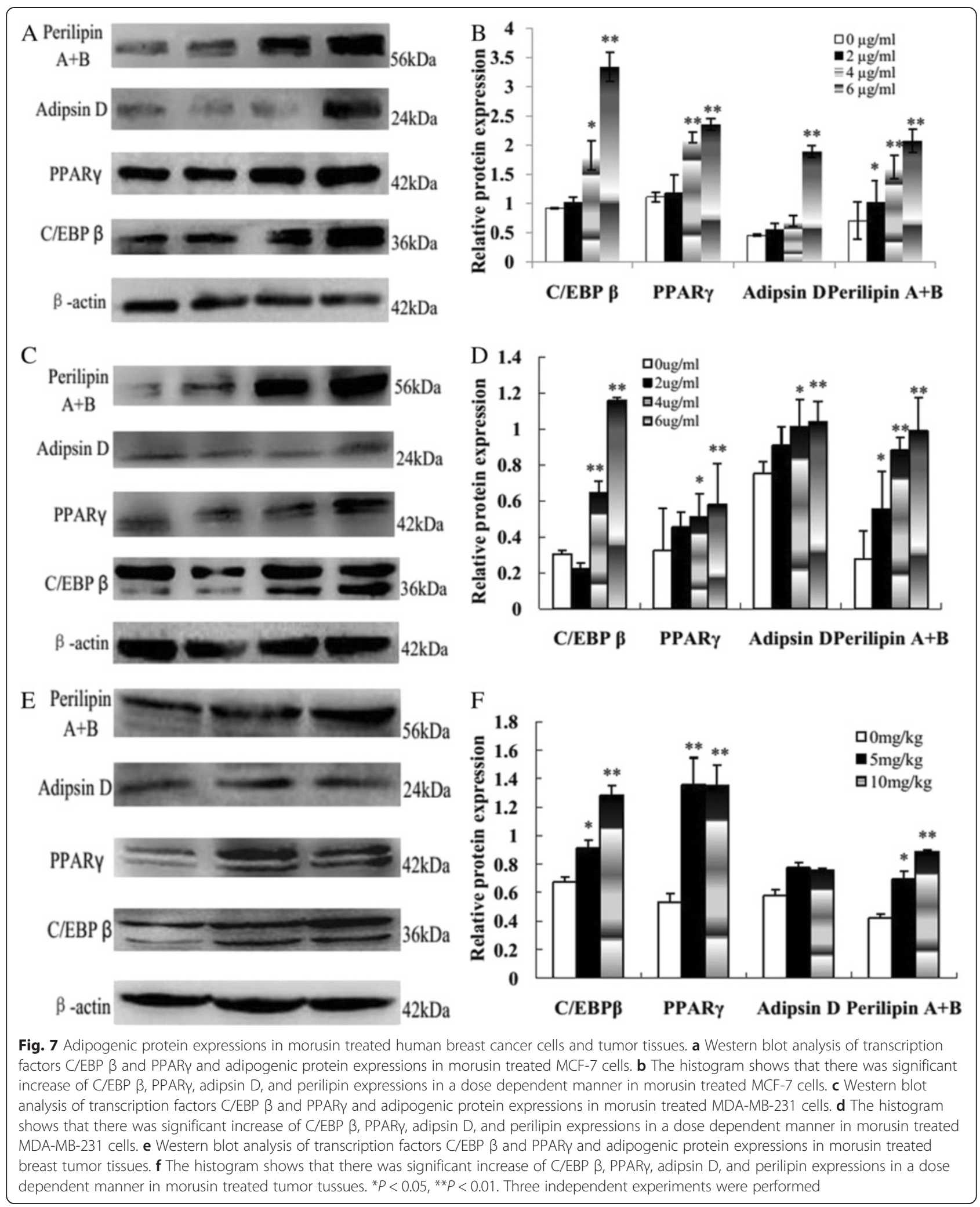

and PPAR $\gamma$, adipogenic and apoptotic proteins in morusin treated cancer cells and tumor tissues were analyzed with Western blotting. After morusin treatment, transcription factors C/EBP $\beta$ and PPAR $\gamma$, adipogenic proteins including adipsin $\mathrm{D}$ and perilipin were increased significantly $(p<0.05$, Fig. 7$)$ both in morusin treated 


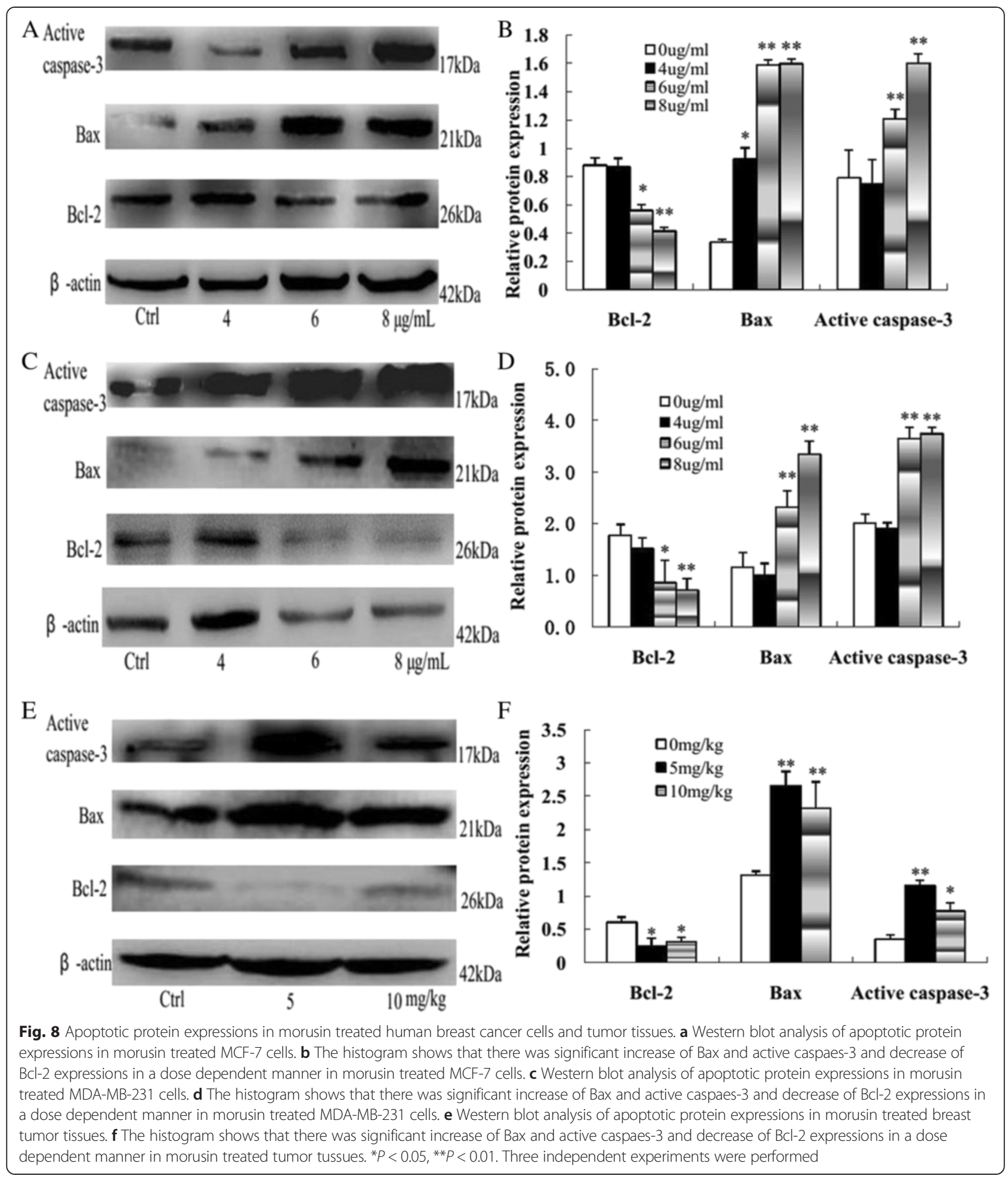

cancer cells and tumor tissues, which were widely used molecular markers of adipocyte differentiation [36-39]; In apoptotic protein expression, anti-apoptosis protein, Bcl-2 were decreased, pro-apoptosis protein, bax and active caspaes-3 were increased significantly $(p<0.05$, Fig. 8$)$, which play important roles in the regulation of mitochondrial-mediated apoptosis [40, 41].

CCAAT-enhancer binding protein $\beta(C / E B P \beta)$ plays a pivotal role in terminal adipocyte differentiation, it is induced early to transactivate the expression of two master 
transcription factors, $\mathrm{C} / \mathrm{EBP} \alpha$ and peroxisome proliferatoractivated receptor $\gamma$ (PPAR $\gamma$ ) [42]. Besides, C/EBP $\beta$ is also a transcription factor necessary for growth and differentiation of mammary gland and plays a critical role in mammary gland development and breast cancer progression $[43,44]$. Its expression decrease was associated with shorter overall survival of breast cancer patients and increase of lung metastasis of mouse breast cancer cells $[44,45]$. Herein, morusin might act as an agonist of $\mathrm{C} / \mathrm{EBP} \beta$ and PPAR $\gamma$, upregulate expressions of C/EBP $\beta$ and PPARy, activated the cascade of adipogenic differentiation of breast cancer cells.

Moreover, PPAR $\gamma$ activation is associated with differentiation, proliferation inhibition of the normal and malignant cells [46] and reversal of malignant phenotype of breast cancer cells [47]. It plays potential roles in the apoptosis of many types of cancer cells; its expression was increased simultaneously when apoptosis occurred [47-51].

In this experimental study, morusin treatment forced breast cancer cells differentiated into adipocyte-like cells, a lot of lipid droplets were accumulated increasingly in these adipogenic differentiating cells, unlimited accumulation of lipid droplets in the differentiating cancer cells results in apoptotic cell death of the differentiated cancer cells due to lipoptosis [52, 53]. Lipoptosis induction might be a novel approach for cancer therapeutic strategy, but no agents, which directly induce lipoapoptosis of cancer cells, have thus far been identified [52-54].

Combined with the findings in the present study, it could be assumed that morusin might be an effective agent on inducing adipogenic differentiation and lipoapoptosis of breast cancer cells through modulating the pathways of adipogenic differentiation and apoptosis or lipoapoptosis.

\section{Conclusions}

In summary, morusin has the potential to inhibit human breast cancer cells growth in vitro and in vivo through $\mathrm{C} / \mathrm{EBP} \beta$ and PPAR $\gamma$ mediated adipogenic differentiation and lipoapoptosis induction, it might serve as a novel therapeutic agent for the treatment and/or prevention of human breast cancer, including ER+ breast cancer and $\mathrm{TNBC}$, and need to be investigated further.

\section{Competing interests}

The authors have declared that no competing interests exist.

\section{Authors' contributions}

$H L, Q W, L Q$, performed cell biology experiment; $L D, C L$ performed animal experiment; ZS, NG participated cell biology and animal experiment; XW conceived of the study, and participated in its design and coordination and helped to draft the manuscript. All authors read and approved the final manuscript.

\section{Acknowledgement}

This work was supported by the Research Foundation of Science and Technology Bureau of Sichuan Province, China (Grant No. 2014SZ0001).
Received: 14 September 2015 Accepted: 28 October 2015

Published online: 04 November 2015

\section{References}

1. Tao Z, Shi A, Lu C, Song T, Zhang Z, Zhao J. Breast Cancer: Epidemiology and Etiology. Cell Biochem Biophys. 2014. [Epub ahead of print]

2. Confortini CC, Krong B. Breast cancer in the global south and the limitations of a biomedical framing: a critical review of the literature. Health Policy Plan. 2015. [Epub ahead of print].

3. Mittra I. Breast cancer screening in developing countries. Prev Med. 2001;53:121-2

4. Zhou X, Wang X, Huang Z, Xu L, Zhu W, Liu P. An ER-associated miRNA signature predicts prognosis in ER-positive breast cancer. J Exp Clin Cancer Res. 2014;33:94.

5. Madhavan S, Gusev Y, Singh S, Riggins RB. ERRY target genes are poor prognostic factors in Tamoxifen-treated breast cancer. J Exp Clin Cancer Res. 2015;34:45.

6. Pandiella A, Morís F, Ocaña A, Núñez LE, Montero JC. Antitumoral activity of the mithralog EC-8042 in triple negative breast cancer linked to cell cycle arrest in G2. Oncotarget. 2015. [Epub ahead of print]

7. Karami F, Mohammadi-Yeganeh S, Abedi N, Koochaki A, Kia V, Paryan M. Bioinformatics prediction and in vitro analysis revealed that miR-17 targets Cyclin D1 mRNA in Triple NegativeBreast Cancer cells. Chem Biol Drug Des. 2015. doi: 10.1111/cbdd.12671. [Epub ahead of print]

8. Bastian A, Thorpe JE, Disch BC, Bailey-Downs LC, Gangjee A, Devambatla RK, et al. A small molecule with anticancer and antimetastatic activities induces rapid mitochondrial associated necrosis in breast cancer. J Pharmacol Exp Ther. 2015;353:392-404.

9. de Lartigue J. Moving beyond the one-size-fits-all formula for breast cancer treatments. J Community Support Oncol. 2014;12:301-7.

10. Shen $Y$, Du Y, Zhang Y, Pan Y. Synergistic effects of combined treatment with simvastatin and exemestane on MCF-7 human breast cancer cells. Mol Med Rep. 2015;12:456-62.

11. Palma G, Frasci G, Chirico A, Esposito E, Siani C, Saturnino C, et al. Triple negative breast cancer: looking for the missing link between biology and treatments. Oncotarget. 2015;6:26560-74.

12. Mukherjee AK, Basu S, Sarkar N, Ghosh AC. Advances in cancer therapy with plant based natural products. Curr Med Chem. 2001;8:1467-86.

13. Wang S, Penchala S, Prabhu S, Wang J, Huang Y. Molecular basis of traditional Chinese medicine in cancer chemoprevention. Curr Drug Discov Technol. 2010;7:67-75.

14. Nabavi SM, Habtemariam S, Daglia M, Nabavi SF. Apigenin and breast cancers: from chemistry to medicine. Anticancer Agents Med Chem. 2015;15:728-35.

15. Lee JC, Won SJ, Chao CL, Wu FL, Liu HS, Ling P, et al. Morusin induces apoptosis and suppresses NF-kappaB activity in human colorectal cancer HT-29 cells. Biochem Biophys Res Commun. 2008;372:236-42.

16. Wan LZ, Ma B, Zhang YQ. Preparation of morusin from Ramulus mori and its effects on mice with transplanted $\mathrm{H} 22$ hepatocarcinoma. Biofactors 2014;40:636-45.

17. Lim SL, Park SY, Kang S, Park D, Kim SH, Um JY, et al. Morusin induces cell death through inactivating STAT3 signaling in prostate cancer cells. Am J Cancer Res. 2014:25:289-99.

18. Dat NT, Binh PT, le Quynh TP, Van Minh C, Huong HT, Lee JJ. Cytotoxic prenylated flavonoids from Morus alba. Fitoterapia. 2010;81:1224-7.

19. Lin WL, Lai DY, Lee YJ, Chen NF, Tseng TH. Antitumor progression potential of morusin suppressing STAT3 and NFKB in human hepatoma SK-Hep1 cells. Toxicol Lett. 2015;232:490-8.

20. Lee HJ, da Lyu H, Koo U, Nam KW, Hong SS, Kim KO, et al. Protection of prenylated flavonoids from Mori Cortex Radicis (Moraceae) against nitric oxide-induced cell death in neuroblastoma SH-SY5Y cells. Arch Pharm Res. 2012;35:163-70.

21. Wang L, Guo H, Yang L, Dong L, Lin C, Zhang J, et al. Morusin inhibits human cervical cancer stem cell growth and migration through attenuation of NF-kB activity and apoptosis induction. Mol Cell Biochem. 2013;379:7-18.

22. Guo H, Liu C, Yang L, Dong L, Wang L, Wang Q, et al. Morusin inhibits glioblastoma stem cell growth in vitro and in vivo through stemness attenuation, adipocyte transdifferentiation, and apoptosis induction. Mol Carcinog. 2014. doi: 10.1002/mc.22260. [Epub ahead of print]

23. van Meerloo J, Kaspers GJ, Cloos J. Cell sensitivity assays: the MTT assay. Methods Mol Biol. 2011;731:237-45. 
24. Ebrahim K, Shirazi FH, Vatanpour H, Zare A, Kobarfard F, Rabiei H. Anticancer activity of Cobra Venom polypeptide, cytotoxin-II, against human breast adenocarcinoma cell line (MCF-7) via the induction of apoptosis. J Breast Cancer. 2014:17:314-22.

25. Zhang H, Xu HL, Fu WW, Xin Y, Li MW, Wang SJ, et al. 20(S)-Protopanaxadiol induces human breast cancer MCF-7 apoptosis through a caspase-mediated pathway. Asian Pac J Cancer Prev. 2014;15:7919-23.

26. Tsai CH, Lin FM, Yang YC, Lee MT, Cha TL, Wu GJ, et al. Herbal extract of Wedelia chinensis attenuates androgen receptor activity and orthotopic growth of prostate cancer in nude mice. Clin Cancer Res. 2009;15:5435-44.

27. Münster PN, Srethapakdi M, Moasser MM, Rosen N. Inhibition of heat shock protein 90 function by ansamycins causes the morphological and functional differentiation of breast cancer cells. Cancer Res. 2001;61:2945-52.

28. Doherty MK, Morris PG. Eribulin for the treatment of metastatic breast cancer: an update on its safety and efficacy. Int J Womens Health. 2015;7:47-58.

29. Sak K. Cytotoxicity of dietary flavonoids on different human cancer types. Pharmacogn Rev. 2014;8:122-46.

30. Yeap S, Akhtar MN, Lim KL, Abu N, Ho WY, Zareen S, et al. Synthesis of an anthraquinone derivative (DHAQC) and its effect on induction of G2/M arrest and apoptosis in breast cancer MCF-7 cell line. Drug Des Devel Ther 2015;9:983-92.

31. Wang $L$, Peng $Y$, Shi $K$, Wang $H$, Lu J, Li Y , et al. Osthole inhibits proliferation of human breast cancer cells by inducing cell cycle arrest and apoptosis. J Biomed Res. 2015:29:132-8.

32. Tengku Din TA, Seeni A, Khairi WN, Shamsuddin S, Jaafar H. Effects of rapamycin on cell apoptosis in mcf-7 human breast cancer cells. Asian Pac J Cancer Prev. 2014;15:10659-63.

33. Baharara J, Namvar F, Ramezani T, Mousavi M, Mohamad R. Silver Nanoparticles Biosynthesized Using Achillea biebersteinii Flower Extract: Apoptosis Induction in MCF-7 Cells via Caspase Activation and Regulation of Bax and Bcl-2 Gene Expression. Molecules. 2015;20:2693-706.

34. Minamino $M$, Oka $T$, Kanouchi $H$. Growth suppression and cell death by pyridoxal is dependent on p53 in the human breast cancer cell line MCF-7. Biosci Biotechnol Biochem. 2015;79:124-9.

35. Chiu CC, Haung JW, Chang FR, Huang KJ, Huang HM, Huang HW, et al. Golden berry-derived $4 \beta$-hydroxywithanolide $E$ for selectively killing oral cancer cells by generating ROS, DNA damage, and apoptotic pathways. PLOS ONE. 2013;8:e64739.

36. Yan J, Luo D, Luo Y, Gao X, Zhang G. Induction of G1 arrest and differentiation in MDA-MB-231 breast cancer cell by boehmeriasin A, a novel compound from plant. Int J Gynecol Cancer. 2006;16:165-70.

37. Demetri GD, Fletcher CD, Mueller E, Sarraf P, Naujoks R, Campbell N, et al. Induction of solid tumor differentiation by the peroxisome proliferatoractivated receptor-gamma ligand troglitazone in patients with liposarcoma. Proc Natl Acad Sci U S A. 1999;96:3951-6.

38. MacDougald OA, Lane MD. Transcriptional regulation of gene expression during adipocyte differentiation. Annu Rev Biochem. 1995;64:345-73.

39. Thompson WR, Guilluy C, Xie Z, Sen B, Brobst KE, Yen SS, et al. Mechanically activated Fyn utilizes $\mathrm{mTORC} 2$ to regulate RhoA and adipogenesis in mesenchymal stem cells. Stem Cells. 2013;31:2528-37.

40. Hu W, Lee SK, Jung MJ, Heo SI, Hur JH, Wang MH. Induction of cell cycle arrest and apoptosis by the ethyl acetate fraction of Kalopanax pictus leaves in human colon cancer cells. Bioresour Technol. 2010;101:9366-72.

41. Sun B, Geng S, Huang X, Zhu J, Liu S, Zhang Y, et al. Coleusin factor exerts cytotoxic activity by inducing G0/G1 cell cycle arrest and apoptosis in human gastric cancer BGC-823 cells. Cancer Lett. 2011;301:95-105.

42. Guo L, Li X, Tang QQ. Transcriptional regulation of adipocyte differentiation: a central role for CCAAT/enhancer-binding protein (C/EBP) $\beta$. J Biol Chem. 2015:290:755-61.

43. Zahnow CA. CCAAT/enhancer binding proteins in normal mammary development and breast cancer. Breast Cancer Res. 2002;4:113-21.

44. Kurzejamska E, Johansson J, Jirström K, Prakash V, Ananthaseshan S, Boon L, et al. C/EBP $\beta$ expression is an independent predictor of overall survival in breast cancer patients by MHCII/CD4-dependent mechanism of metastasis formation. Oncogenesis. 2014;3:e125.

45. Johansson J, Berg T, Kurzejamska E, Pang MF, Tabor V, Jansson M, et al. MiR-155-mediated loss of C/EBP $\beta$ shifts the TGF- $\beta$ response from growth inhibition to epithelial-mesenchymal transition, invasion and metastasis in breast cancer. Oncogene. 2013;32:5614-24.
46. Costa V, Foti D, Paonessa F, Chiefari E, Palaia L, Brunetti G, et al. The insulin receptor: a new anticancer target for peroxisome proliferator-activated receptor-gamma(PPARgamma) and thiazolidinedione-PPARgamma agonists. Endocr Relat Cancer. 2008;15:325-35.

47. Zheng ZH, Yang Y, Lu XH, Zhang H, Shui XX, Liu C, et al. Mycophenolic acid induces adipocyte-like differentiation and reversal of malignancy of breast cancer cells partly through PPARy. Eur J Pharmacol. 2011;658:1-8.

48. Chang TH, Szabo E. Induction of differentiation and apoptosis by ligands of peroxisome proliferator-activated receptor gamma in non-small cell lung cancer. Cancer Res. 2000;50:1129-38.

49. Clay CE, Namen AM, Atsumi G, Willingham MC, High KP, Kute TE, et al. Influence of J series prostaglandins on apoptosis and tumorigenesis of breast cancer cells. Carcinogenesis. 1999;20:1905-11.

50. Martinasso G, Oraldi M, Trombetta A, Maggiora M, Bertetto O, Canuto RA, et al. Involvement of PPARs in cell proliferation and apoptosis in human colon cancer specimens and in normal and cancer cell lines. PPAR Res. 2007;2007:93416.

51. Tsubouchi Y, Sano H, Kawahito Y, Mukai S, Yamada R, Kohno M, Inoue K, et al. (2000) Inhibition of human lung cancer cell growth by the peroxisome proliferator-activated receptor-gamma agonists through induction of apoptosis. Biochem Biophys Res Commun. 2000;270:400-5.

52. Pohle T, Brändlein S, Ruoff N, Müller-Hermelink HK, Vollmers HP. Lipoptosis: tumor-specific cell death by antibody-induced intracellular lipid accumulation. Cancer Res. 2004;64:3900-6.

53. Schaffer JE. Lipotoxicity: when tissues overeat. Curr Opin Lipidol. 2003;14:281-7.

54. Zhang Z, Zhou Y, Qian H, Shao G, Lu X, Chen Q, et al. Stemness and inducing differentiation of small cell lung cancer NCl-H446 cells. Cell Death Dis. 2013;4:e633.

\section{Submit your next manuscript to BioMed Central and take full advantage of:}

- Convenient online submission

- Thorough peer review

- No space constraints or color figure charges

- Immediate publication on acceptance

- Inclusion in PubMed, CAS, Scopus and Google Scholar

- Research which is freely available for redistribution 